\title{
, \\ A VIN3-like Protein OsVIL1 Is Involved in Grain Yield and Biomass in Rice
}

\author{
Jinmi Yoon ${ }^{1,2,+}$, Hee-Joong Jeong ${ }^{2,+}$, Gibeom Baek ${ }^{1}$, Jungil Yang ${ }^{2}$, Xin Peng ${ }^{2,3}$, Win Tun ${ }^{2}$, Sun-Tae Kim ${ }^{1}{ }^{1}$, \\ Gynheung An ${ }^{2, *}$ and Lae-Hyeon Cho ${ }^{1, *}$
}

1 Department of Plant Bioscience, Life and Industry Convergence Research Institute, Pusan National University, Miryang 50463, Korea; jmjh0120@khu.ac.kr (J.Y.); bakki96@pusan.ac.kr (G.B.); stkim71@pusan.ac.kr (S.-T.K.)

2 Crop Biotech Institute and Graduate School of Biotechnology, Kyung Hee University, Yongin 17104, Korea; hjjung@postech.ac.kr (H.-J.J.); rnlwo@postech.ac.kr (J.Y.); xinpenglyl@163.com (X.P.); wintun@khu.ac.kr (W.T.)

3 Institution of Genomics and Bioinformatics, South China Agricultural University, Guangzhou 510642, China

* Correspondence: genean@khu.ac.kr (G.A.); lhcho@pusan.ac.kr (L.-H.C.)

+ These authors contributed equally to this work.

check for

updates

Citation: Yoon, J.; Jeong, H.-J.; Baek,

G.; Yang, J.; Peng, X.; Tun, W.; Kim,

S.-T.; An, G.; Cho, L.-H. A VIN3-like

Protein OsVIL1 Is Involved in Grain

Yield and Biomass in Rice. Plants

2022, 11, 83. https://doi.org/

10.3390/plants11010083

Academic Editors: Yin Li,

Guangxiao Yang, Yongfang Wan,

Jian Zeng and Yaqiong Wang

Received: 26 November 2021

Accepted: 26 December 2021

Published: 28 December 2021

Publisher's Note: MDPI stays neutral with regard to jurisdictional claims in published maps and institutional affiliations.

Copyright: (c) 2021 by the authors. Licensee MDPI, Basel, Switzerland. This article is an open access article distributed under the terms and conditions of the Creative Commons Attribution (CC BY) license (https:// creativecommons.org/licenses/by/ $4.0 /)$.

\begin{abstract}
In chromatin remodeling, the post-translational modification of histone proteins is mediated by multimeric protein complexes. VERNALIZATION INSENSITIVE3 (VIN3) forms a complex with Polycomb Repressive Complex 2 (PRC2), which mediates the trimethylation of H3K27 to repress target gene expression. In rice, four genes (OsVIL1-OsVIL4) encoding the VIN3-like proteins are expressed ubiquitously in various tissues. Null mutants of osvil2 display pleiotropic phenotypes such as altered flowering time, floral organ defects, and reduced tiller size. In contrast, osvil1 mutants did not show significant phenotypes except in fertilization compared with the wild type. However, transgenic plants overexpressing OsVIL1 showed phenotypes of increased biomass and grain yield. Cross-sections of the basal region of elongating stems revealed that the increased biomass was mediated by inducing cell proliferation in the meristem. Chromatin immunoprecipitation assay indicated that OsVIL1 repressed expression of cytokinin oxidase/dehydrogenase gene (OsCKX2) by binding to the promoter and genic regions of OsCKX2. We also observed that OsVIL1 modified the levels of $\mathrm{H} 3 \mathrm{~K} 27 \mathrm{me} 3$ in the OsCKX2 chromatin. Because OsCKX2 encodes an enzyme that degrades active cytokinin, we conclude that OsVIL1 functions in the regulation of endogenous active cytokinin levels, thereby increasing plant height and productivity.
\end{abstract}

Keywords: rice; grain yield; biomass; histone modification; OsVIL1; OsCKX2

\section{Introduction}

Rice is a staple food, and increasing productivity of this crop is an important agricultural goal. To this end, much research has been carried out on increasing rice grain yield. In rice, plant architecture is an important factor that determines productivity, which is well known to depend on meristem activity [1,2]. Cytokinins are important in regulating meristem activity and maintenance by increasing cell division [1-5]. LONELY GUY (LOG) encodes a cytokinin riboside $5^{\prime}$-monophosphate phosphoribohydrolase that functions during the final step in bioactive cytokinin synthesis [3]. LOG mutants exhibit defective maintenance of shoot meristems and a severe reduction in panicle size [3]. The most effective QTL for increasing grain yield, GRAIN NUMBER 1a (Gn1a), encodes cytokinin oxidase/dehydrogenase (OsCKX2), which degrades active cytokinin [6]. Decreased expression of $\mathrm{OsCKX}_{\mathrm{S}}$ causes cytokinin to accumulate in inflorescence meristems and leads to a large number of tillers and spikelets per plant $[6,7]$. Several factors that influence grain productivity and biomass are associated with $O s C K X 2$ regulation [6-8]. The zinc-finger transcription factor DROUGHT AND SALT TOLERANCE (DST) directly activates OsCKX2 expression in the meristem [9]. The mutant allele DST ${ }^{\text {reg1 }}$ causes down-regulation of Os$C K X 2$, thus increasing cytokinin accumulation in the inflorescence meristem and increasing 
the number of branches and grains [9]. Also, LARGER PANICLE (LP), which encodes a Kelch repeat-containing F-box protein, improves the panicle architecture and grain yield in rice [10]. LP is an ER-localized protein and interacts with rice SKP-like proteins, suggesting that LP might be involved in ER-associated protein degradation. Mutation of the LP gene reduces the expression of OsCKX2 in young panicles, causing cytokinin accumulation. Also, OsVIL2 represses the expression of OsCKX2 by direct interaction with the promoter region of OsCKX2 [7]. In addition, a chromatin interacting factor OsVIL2 increases panicle development and biomass by increasing active cytokinin levels.

Polycomb repressive complexes contain two major protein complexes, PRC1 and PRC2, in plants [11,12]. PRC2s are methyltransferases that introduce trimethylation of lysine 27 on histone H3 (H3K27me3) to repress down-stream target genes [13,14]. In Arabidopsis, the VERNALIZATION 2 (VRN2)-PRC2 complex has several components: VRN2, SWINGER (an E(Z) Histone Methyltransferase homolog), FERTILIZATION-INDEPENDENT ENDOSPERM (ESC homolog), and Musashi-1 (p55 homolog), which form the canonical part, while three plant-specific PHD (plant homeodomain) finger proteins (VRN5, VERNALIZATION INSENSITIVE3, and VEL1) create the accessory part $[13,15,16]$. Previous reports have indicated that VRN2-PRC2 plays important roles in the vernalization pathway by mediating the accumulation of H3K27me3 at the FLOWERING LOCUS C (FLC) locus after vernalization $[13,17,18]$. The VRN2 complex functions in the vernalization pathway associated with VIN3, VIL1/VRN5, and VIL2 /VERNALIZATION-LIKE 1 [15,19]. VIN3 and VIN3-like proteins consist of conserved domains of the PHD finger, the fibronectin type III domain (FNIII), and the VIN3 interacting domain (VID). The PHD finger recognizes and binds to histone proteins, the FNIII domain is involved in protein-protein interactions, and VID domain is responsible for interactions between other VIL proteins [7,20,21].

Although the vernalization response is not involved in controlling flowering time in rice, it is associated with four VIN3-like proteins: Oryza sativa VIN3-like 1-4 (OsVIL1-4) [7,22]. OsVIL2 binds to O. sativa EMBRYONIC FLOWER 2b (OsEMF2b), a component of PRC2, and the PHD-PRC2 complex induces flowering by repressing O. sativa LEAFY COTYLEDON 2 and FUSCA 3-LIKE 1 (OsLFL1) [23]. Moreover, OsVIL1 binds to OsEMF2b and induces flowering by repressing OsLF under short-day conditions but delays flowering by inducing Grain number, plant height, and heading date 7 (Ghd7) expression under long-day conditions [24,25]. OsVIL2 also plays essential roles in regulating meristem activity and affects biomass, grain yield, tiller outgrowth, and spikelet development $[7,26,27]$. Although both OsVIL1 and OsVIL2 are understood to control flowering time, how OsVIL1 affects other developmental processes has not been studied to date. Here, we focused on how OsVIL1 functions differ from those of OsVIL2, which have already been studied. We showed that OsVIL1 increases grain yield and biomass through the direct regulation of OsCKX2 expression, similarly to OsVIL2.

\section{Results}

2.1. Mutation of OsVIL1 Produces No Obvious Phenotypes in Spikelet Development and Tiller Outgrowth

The rice genome contains four VIN3-like genes: OsVIL1, OsVIL2, OsVIL3, and OsVIL4 (Figure 1A). Interestingly, OsVIL genes extensively existed in higher plants, including lycophytes, gymnosperms, amborellales, eudicots, and monocots, which indicates their functional importance in these plants (Figure 1A). Similar to Arabidopsis VIN3-like proteins, OsVIL1-4 proteins contain PHD, FNIII, and VID domains (Figure 1B). The expression of the four OsVIL genes was broadly detected in various tissues of rice (Figure $1 \mathrm{C}-\mathrm{F}$ and Supplementary Figure S1). 
A

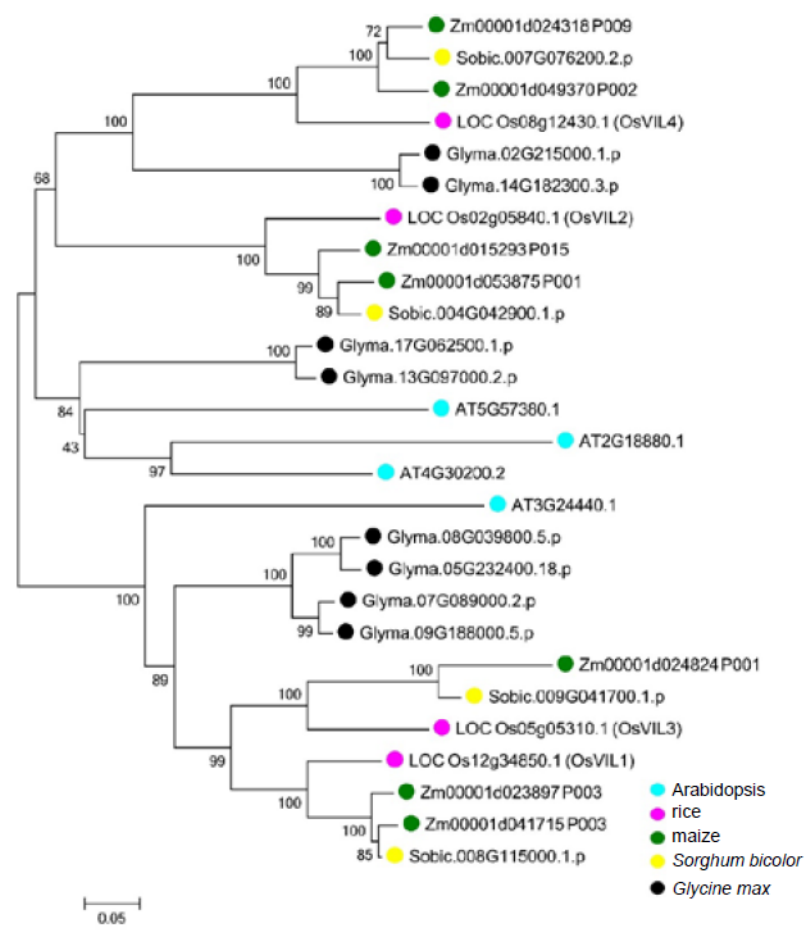

B

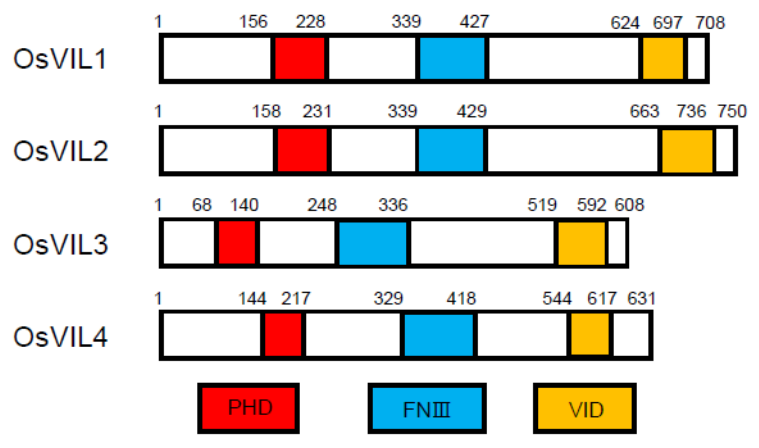

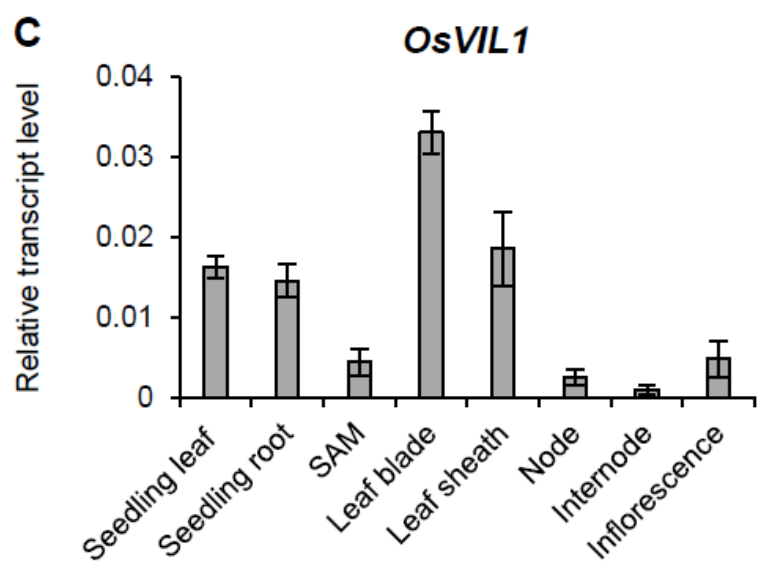
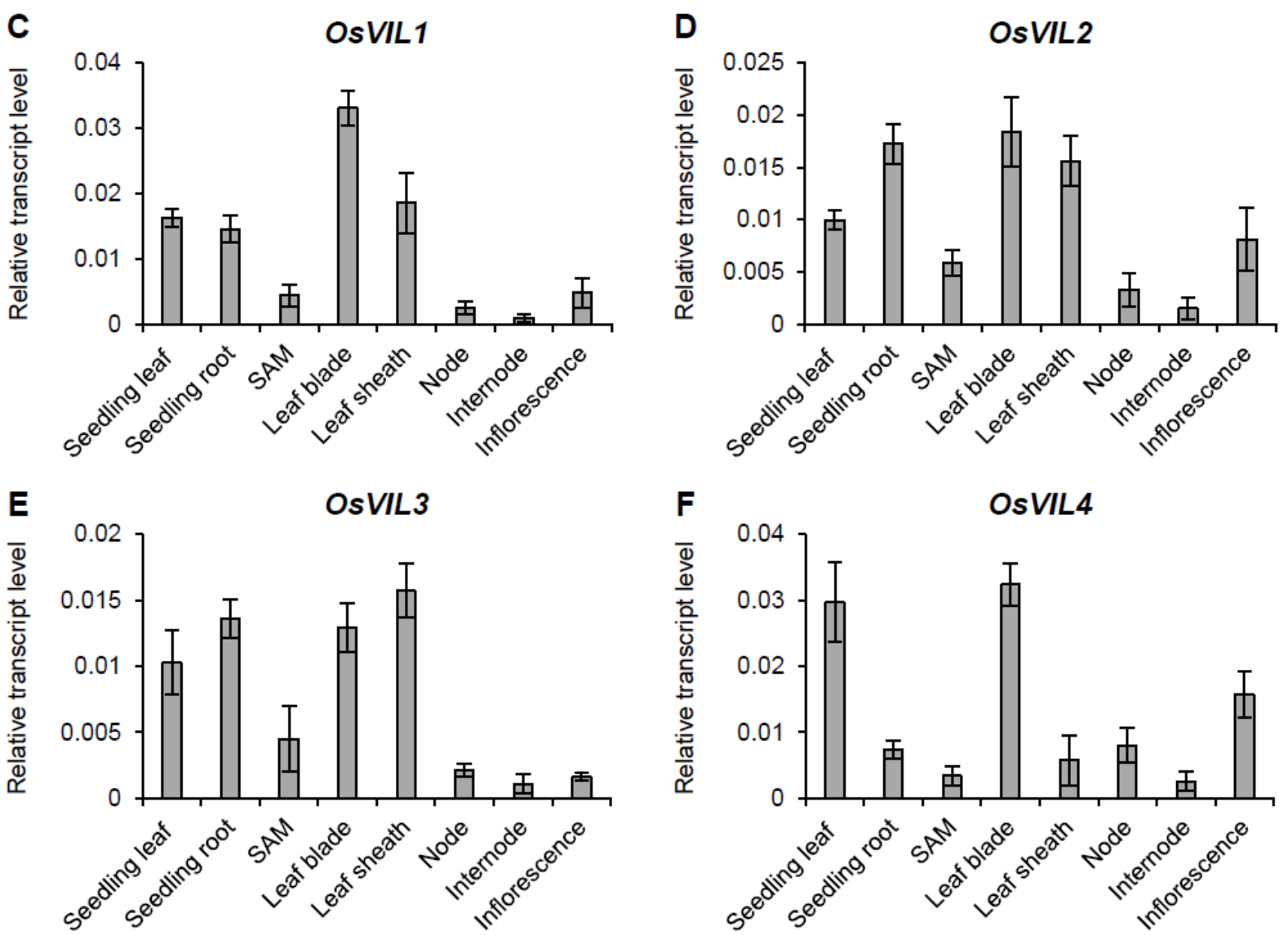

Figure 1. Comparative analysis of OsVIL genes. (A) Phylogenetic analysis of proteins OsVIL1-4 in rice, Arabidopsis, maize, Sorghum bicolor, and Glycine max. (B) Protein structures of OsVIL1-4. (C-F) Expression levels of OsVIL1 (C), OsVIL2 (D), OsVIL3 (E), and OsVIL4 (F) in various tissues. Rice Actin 1 was used as an internal control. The error bars indicate the standard deviations, $n=4$. 
To study the functions of OsVIL1, we generated osvil1 null mutants using the CRISPR/Cas9 method. In the $\mathrm{T}_{2}$ generation, we found three independent lines containing 1-bp insertion that causes early termination of translation (Figure 2A). Compared with the wild type (WT), plant height, and tiller outgrowth were not different in these osvil1 mutants (Figure 2B). The development of panicles and spikelets was also normal in the mutants (Figure 2C-F). Although there were no significant defects in floral organ development, fertility was slightly decreased in the mutants compared with the WT (Figure 2G). These results indicated that OsVIL1 functions redundantly with OsVIL2 in most developmental processes except for a reduction in fertilization.

A

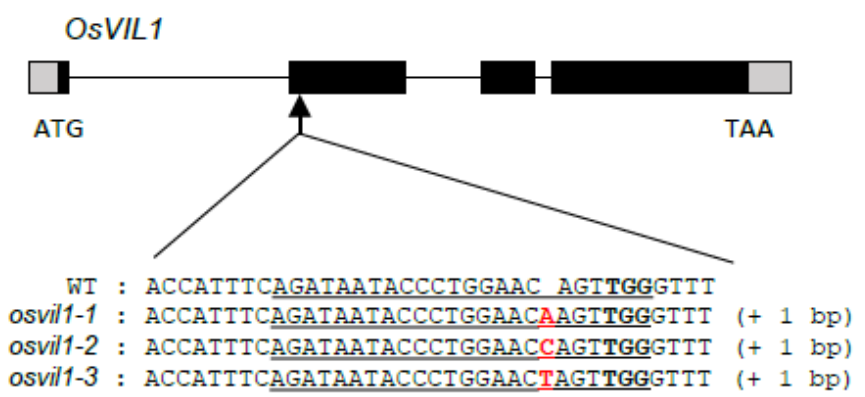

C

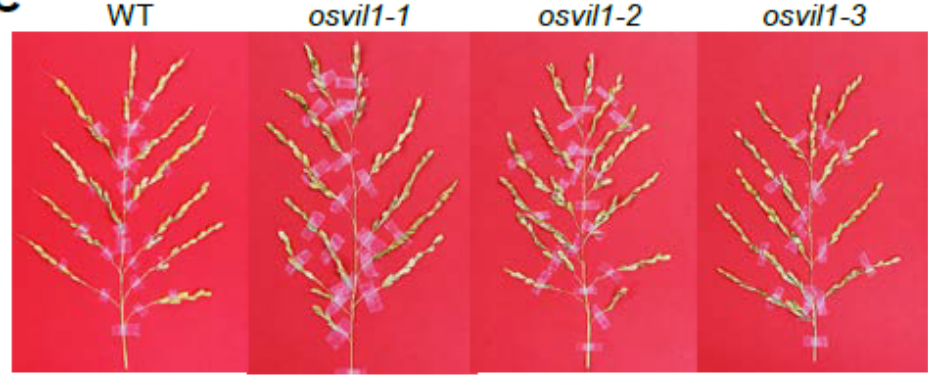

E

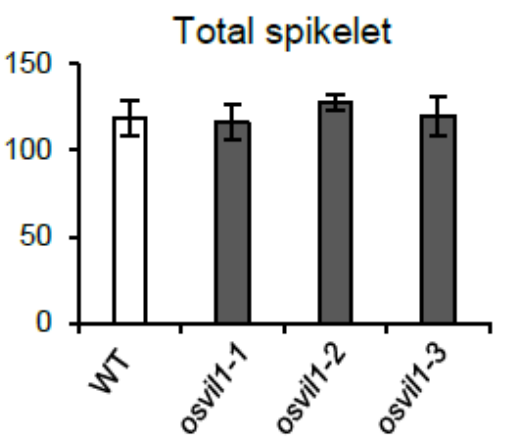

F

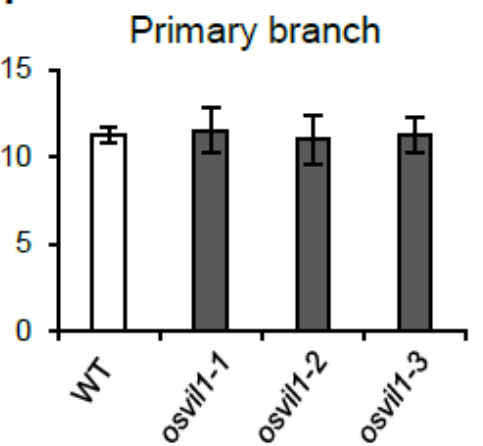

B

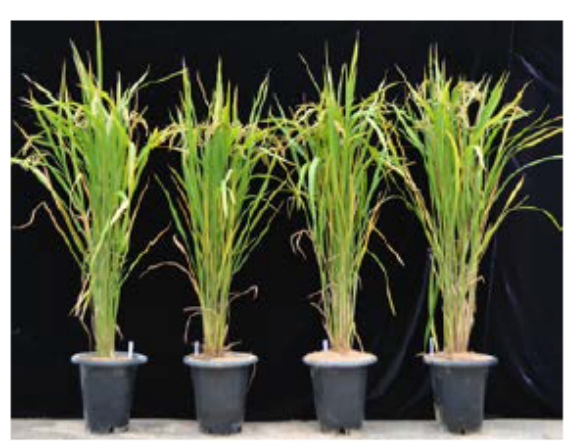

D

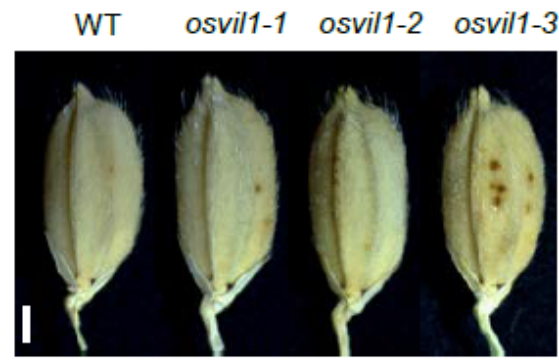

G

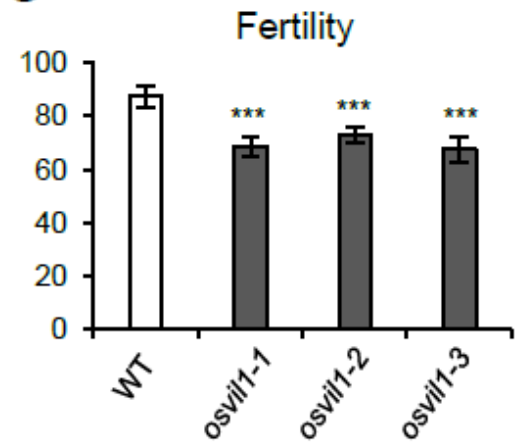

Figure 2. Phenotypes of the wild-type (WT) and osvil1 null mutants. (A) Schematic structure of OsVIL1 and mutation events obtained using the CRISPR/Cas9 method. In the gene structure, the black boxes indicate the four exons and the gray boxes indicate the $5^{\prime} \mathrm{UTR}$ and $3^{\prime} \mathrm{UTR}$ regions. The arrow indicates the mutation sites revealed using the CRISPR/Cas9 method. The target sequence is underlined with the protospacer adjacent motif shown in bold. Altered DNA sequences are indicated in red. (B) Phenotype of plant growth in WT and osvil1 mutants at the seed-ripening stage under paddy field conditions. (C) Panicle phenotypes. Bar $=2 \mathrm{~cm}$. (D) Seed phenotypes. Bar $=1 \mathrm{~mm}$. (E) Total number of spikelets on one panicle. (F) Number of primary branches on the main panicle. (G) Seed fertility. The error bars indicate the standard deviations, $n=$ Statistical significance is indicated by ${ }^{* * *}(p<0.001)$. 


\subsection{Overexpression of OsVIL1 Induces Increased Grain Yield and Biomass}

To determine the function of the other rice VIN3-like proteins, we generated OsVIL1 OX transgenic plants (Figure 3A). Under natural paddy field conditions, the OsVIL1 OX plants showed a $>20 \%$ increase in height compared with the segregated WT (Figure 3B). When each internode length of the WT and OsVIL1 OX plants was measured, we found that the length of each internode was increased in the OX plants compared with the WT (Figure 3C). In addition, two more elongated internodes were observed in the OX plants, indicating that increased plant height of the transgenics was due to increased internode number and length (Figure 3C). Cross-section of the stems showed that the diameter of the main culms was increased in OsVIL1 OX plants when compared with the WT (Figure 3D-F).

A

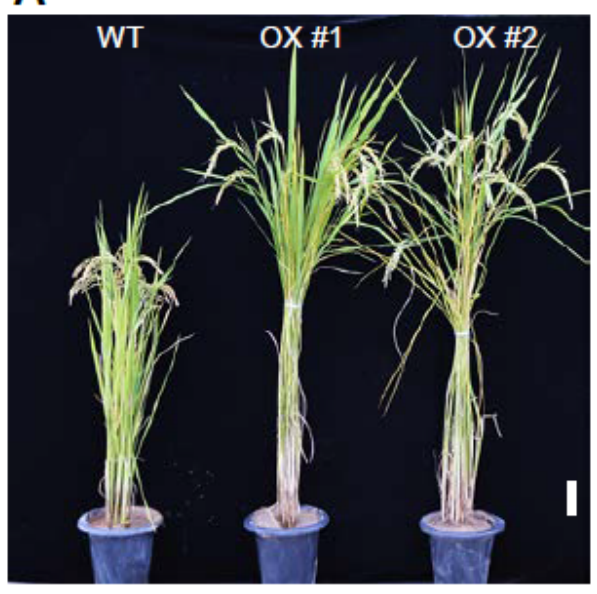

B

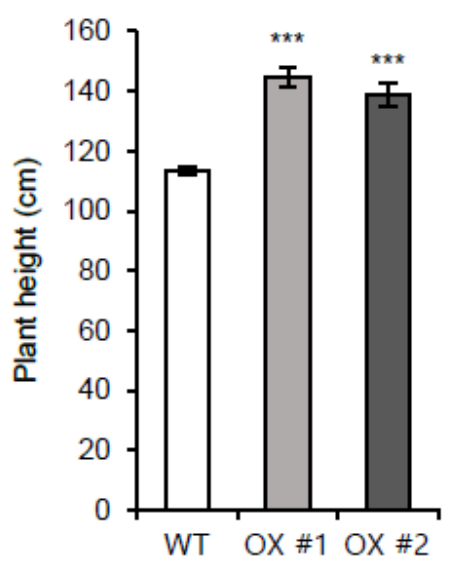

C

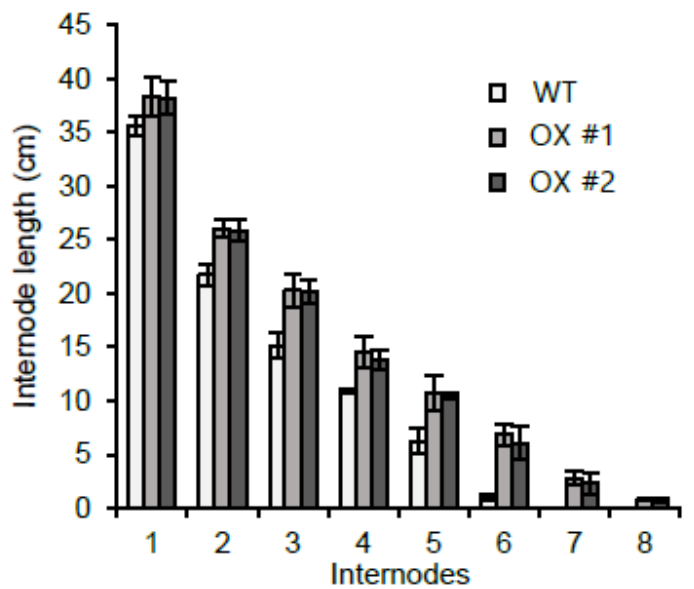

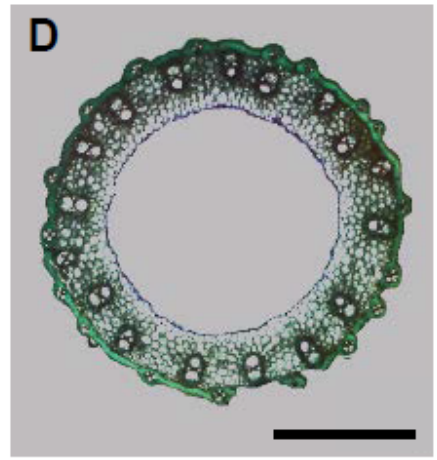

WT

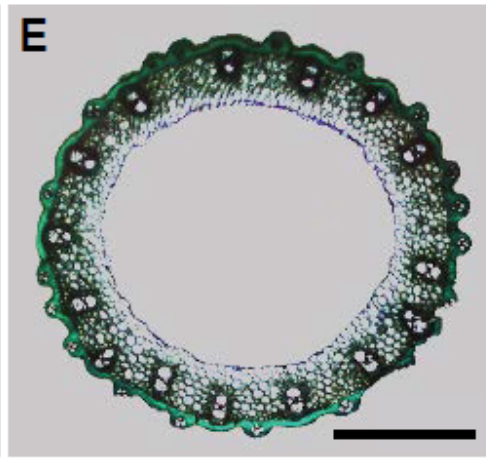

OX \#1

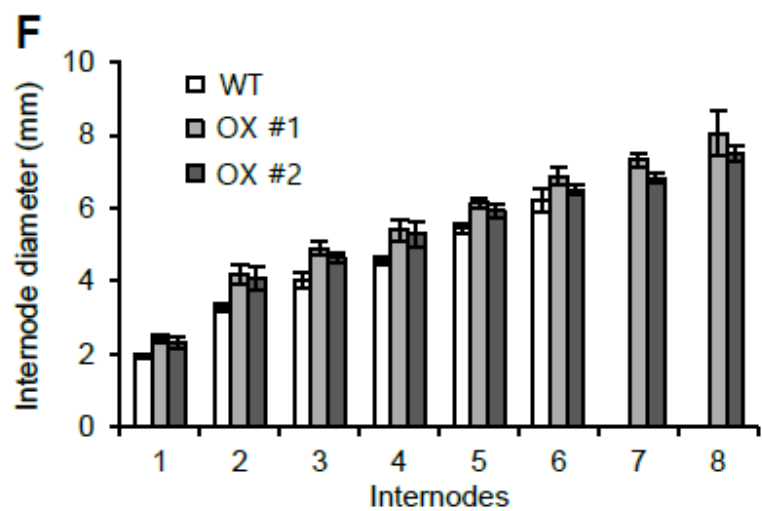

Figure 3. Internode development of wild-type (WT) and OsVIL1 overexpression (OX) transgenic plants. (A) Phenotypes at about 152 days after sowing (DAS) in the paddy field. Bar $=10 \mathrm{~cm}$. (B) Plants height at about 152 DAS. (C) Comparison of each internode length at about 152 DAS. (D,E) Cross sections of the main culm from the first internode of the WT and OsVIL1 OX \#1 transgenic line at about 112 DAS. Bars $=1 \mathrm{~mm}$. (F) Comparison of the internode diameters at about 112 DAS. Error bars indicate the standard deviations, $n=4$ or Statistical significance is indicated by $* * *(p<0.001)$.

Similar to the OsVIL2 OX plants that exhibit increased grain yield, OsVIL1 OX plants showed increased grain yield (Figure 4). OsVIL1 OX lines had larger panicles (Figure 4A,B) and an increased number of primary (Figure 4C) and secondary branches (Figure 4D) compared with the WT. The increased number of primary and secondary branches caused an increase in the total number of spikelets per main panicle (Figure 4E). 
A

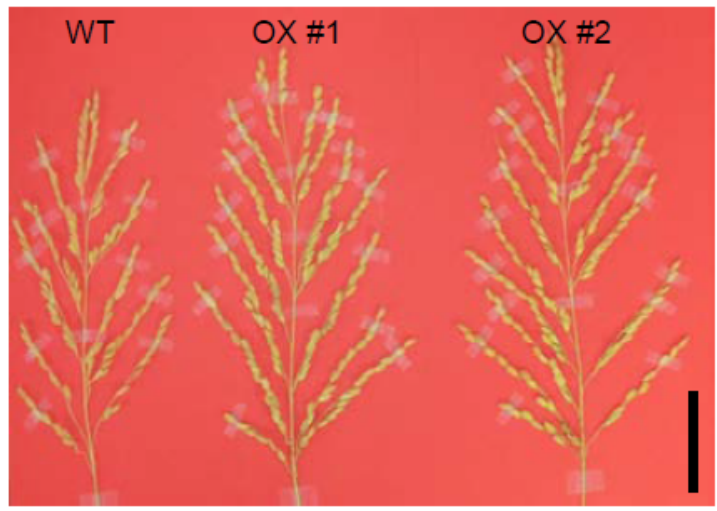

C

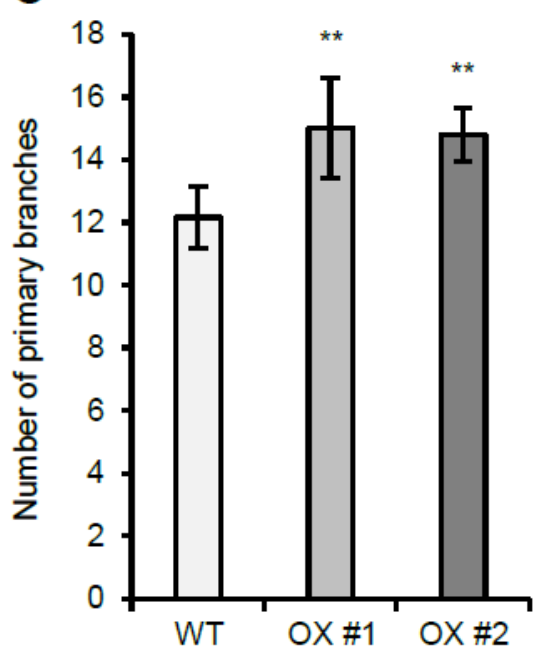

B

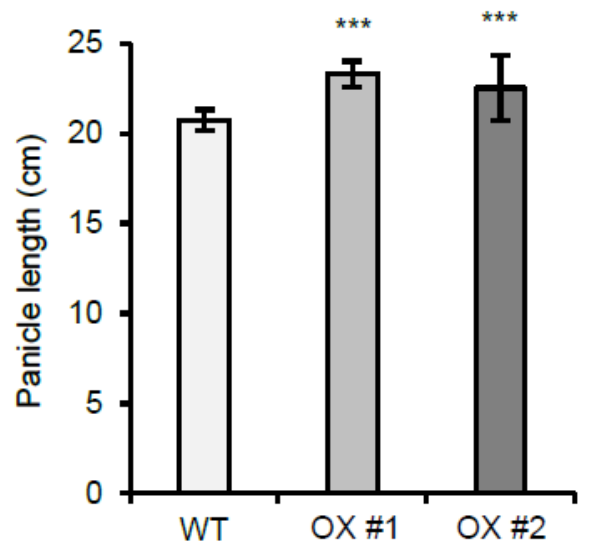

E
D



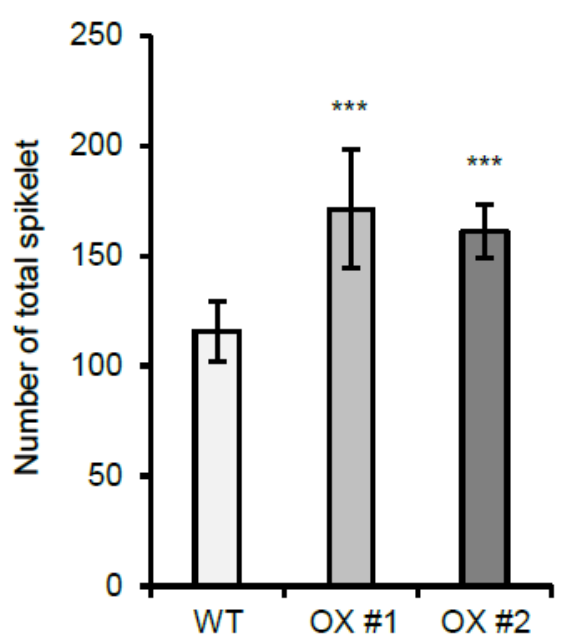

Figure 4. Panicle development in wild-type (WT) and OsVIL1 overexpression (OX) plants. (A) Panicle phenotype of WT and OsVIL1 OX transgenic lines. Bar $=5 \mathrm{~cm}$. (B) Main panicle lengths. (C) Number of primary branches on the main panicle. (D) Number of secondary branches on the main panicle. (E) Total number of spikelets on the main panicle. The error bars indicate the standard deviations, $n=$ Statistical significance is indicated by ${ }^{* * *}(p<0.001){ }^{* *}(p<0.05)$.

\subsection{Overexpression of OsVIL1 Affects Cell Numbers in Meristem Regions}

To investigate the differences between the WT and OsVIL1 OX plants at the cellular level, we analyzed the size and number of the cells in the first internode at about 149 DAS. First, we checked the elongation region of the internode. The longitudinal section of the region showed that the cell number and size in the OsVIL1 OX plants were not significantly increased compared with those of the WT (Figure 5A and Supplementary Figure S2). This observation suggested that increased plant height was not due to cell size. To evaluate whether the increase in plant height observed in the OsVIL1 OX transgenic lines was due to increases in the cell number, the meristem region at the basal parts of the first internode were examined at the about 149 days after sowing (DAS) in the paddy field (Figure 5B). The cell size and number were analyzed in a $0.2-\mathrm{mm}^{2}$ sample area in the division zone after longitudinal sections. The analysis indicated that cell size from the OsVIL1 OX plants was decreased to approximately 52\% and 30\% in length and width, respectively (Figure 5C). In contrast, the cell number was significantly increased to about $180 \%$ in OsVIL1 OX plants compared with the segregated WT (Figure 5D). These results suggested that OsVIL1 promoted cell division in the meristem region of the stem. 
A

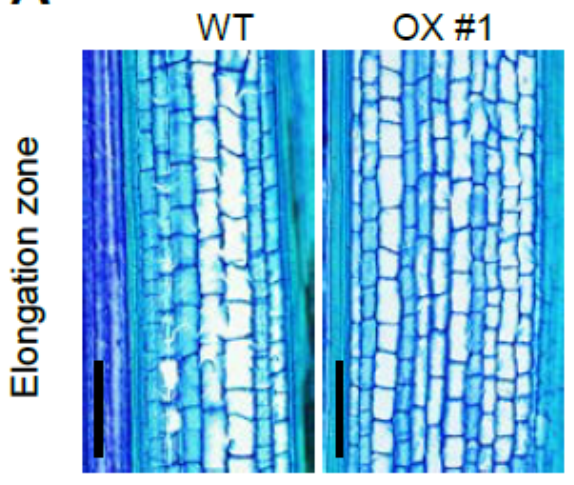

C

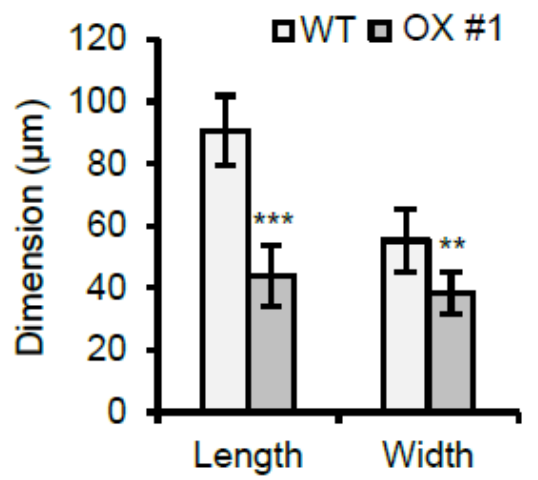

B

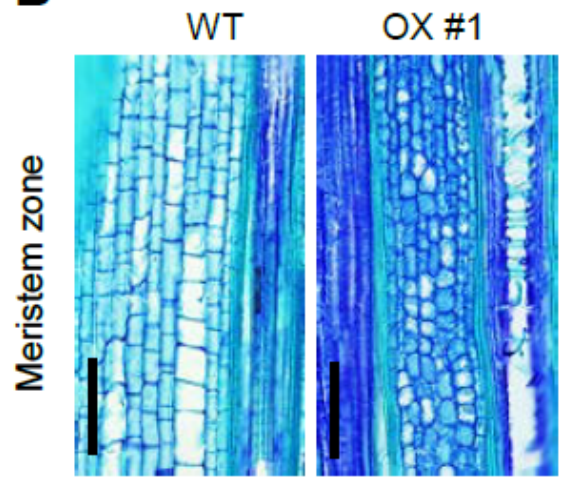

D

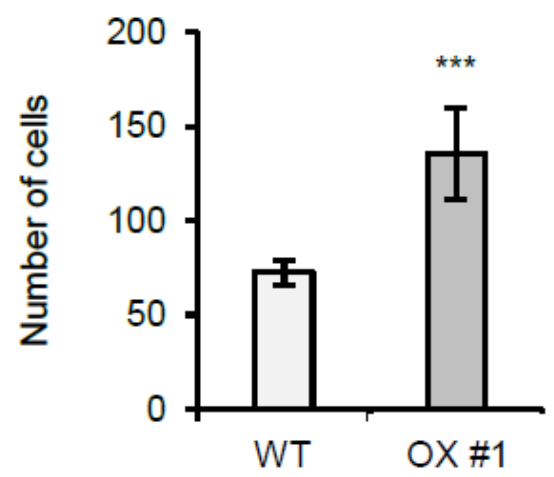

Figure 5. Longitudinal section of the first internode from wild-type (WT) and OsVIL1 overexpression (OX) plants. (A) Longitudinal section analyses of the elongation zone from the first internodes in the WT and OsVIL1 OX \#1 line at about 149 DAS. Bars $=200 \mu \mathrm{m}$. (B) Longitudinal section analyses of the meristem zone from the first internodes at about 149 DAS. Bars $=200 \mu \mathrm{m}$. (C) Comparison of cell length and width in the upper $0.5 \mathrm{~cm}$ of the cell division region in the first internode of the WT and OsVIL1 OX \#1 line, $n=30$ cells from three individual plants. (D) Comparison of cell numbers. Cells were counted in a sample $0.2-\mathrm{mm}^{2}$ area in the meristem region of the internode. The error bars indicate the standard deviations, $n=$ Statistical significance is indicated by ${ }^{* *}(p<0.001),{ }^{* *}(p<0.05)$.

\subsection{OsVIL1 Represses OsCKX2 Expression}

Previously, we showed that gene expression associated with cell division/cell cycle, cell organization, DNA synthesis, and protein synthesis/amino acid activation was increased in OsVIL2 OX plants [7]. We also reported that OsVIL2 suppresses the expression of OsCKX2, which encodes a cytokinin-degrading enzyme [7]. The down-regulation of OsCKX2 causes accumulation of active cytokinin that promotes cell division in OsVIL2 OX plants [7]. Here, we investigated whether OsVIL1 also affected OsCKX2 expression. Analyses of the samples from the cell division zones showed that OsCKX2 expression was significantly reduced in OsVIL1 OX plants compared to WT (Figure 6B). However, the transcript levels of GA 2-oxidase 1 (GA2ox1) that controls GA homeostasis by inactivating bioactive GA through 2 $\beta$-hydroxylation [28] were not significantly altered (Figure 6C). Similarly, the expression levels of $L P, D S T$, and OsSPL14, which regulate panicle size and grain yield [29,30], did not differ between the WT and OsVIL1 OX plants (Figure 6D-F). Our results suggest that OsVIL1 increases active cytokinin levels through the control of OsCKX2 expression. 
A

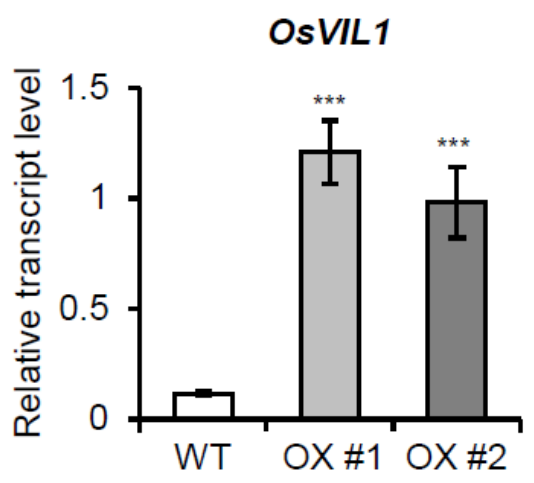

D

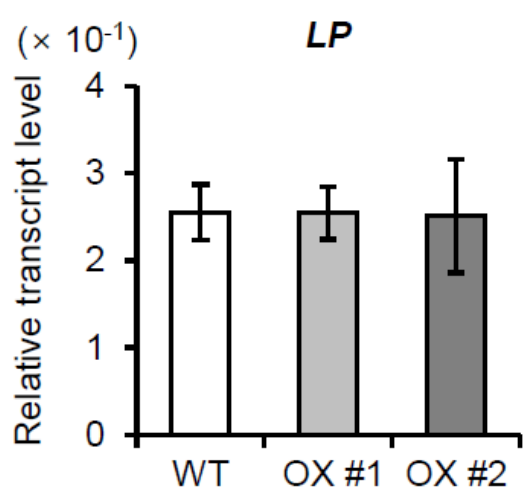

B

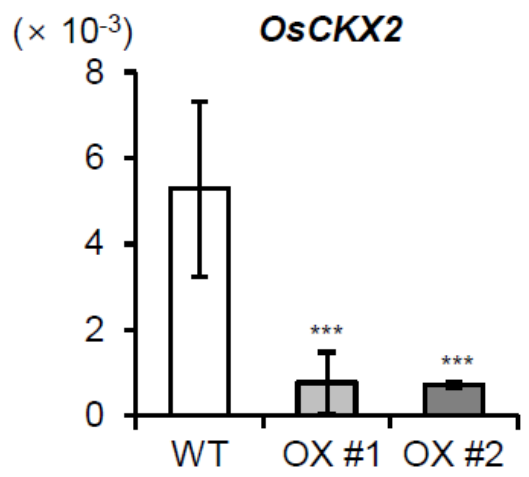

E

$\left(\times 10^{-1}\right)$

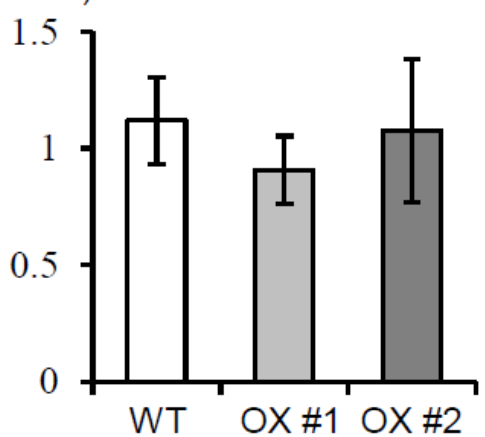

C

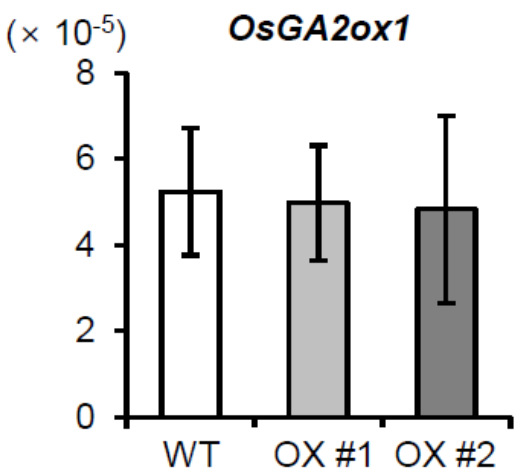

$\mathbf{F}$

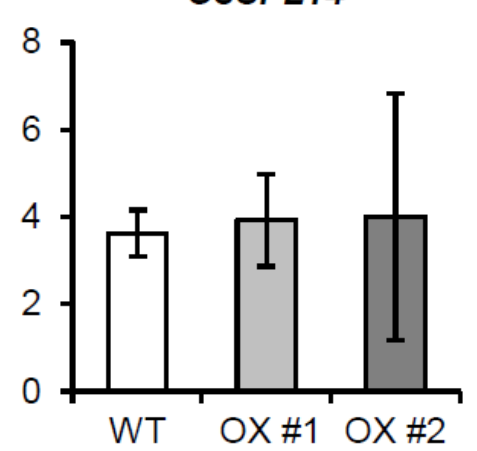

Figure 6. Expression levels of several genes regulating plant height and grain yield in OsVIL1 overexpression $(\mathrm{OX})$ plants. Samples were prepared from the cell division zones $(0.5 \mathrm{~cm})$ of the first internodes $(4 \mathrm{~cm})$ under paddy field conditions. The expression levels of OsVIL1 (A), OsCKX2 (B), OsGA2ox1 (C), OsLP1 (D), OsDST (E), and OsSPL14 (F) in the first internode. Rice Ubiquitin1 was used as an internal control. The error bars indicate the standard deviations, $n=$ Statistical significance is indicated by ${ }^{* * *}(p<0.001)$.

\subsection{OsVIL1 Directly Suppresses OsCKX2 Expression by Regulating H3K27 Chromatin States}

OsVIL2 represses OsCKX2 expression by regulating the chromatin states of H3K27me3 [7]. To investigate whether OsVIL1 also enhances H3K27me3 in OsCKX2 chromatin, we generated transgenic plants that expressed Myc-tagged OsVIL1 as well as Myc alone as a negative control. To perform chromatin immunoprecipitation (ChIP) assay, the basal parts of the second internode were collected before the heading stage. When we observed the levels of H3K27me3 in OsCKX2 chromatin using H3K27me3 antibodies (Figure 7A), the OsCKX2 chromatin was significantly enriched in the OsVIL1-Myc transgenic plants compared with the transgenic plants expressing the Myc-tag alone (Figure 7C). Moreover, when we observed the direct binding of OsVIL1 in the OsCKX2 chromatin region using anti-Myc antibodies, OsVIL1-Myc proteins were enriched at the OsCKX2 chromatin sites P4 and P7-P9 (Figure 7E). As a negative control, we used LP, which was not significantly enriched in the OsVIL1-Myc transgenic plants (Figure 7D,F). 
A

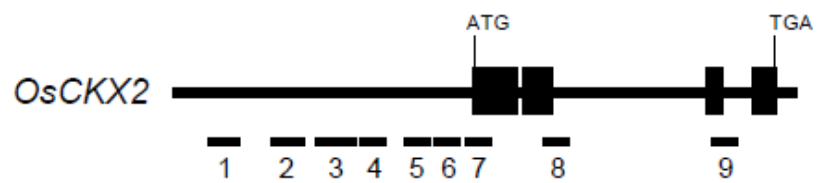

C

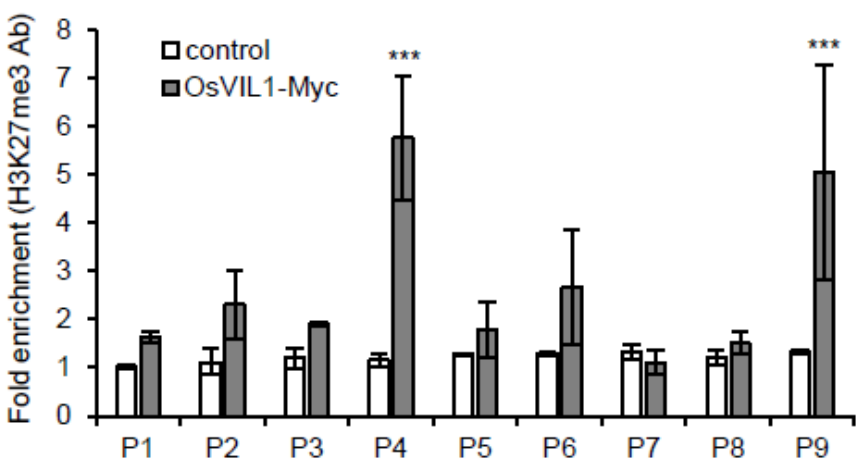

$\mathbf{E}$

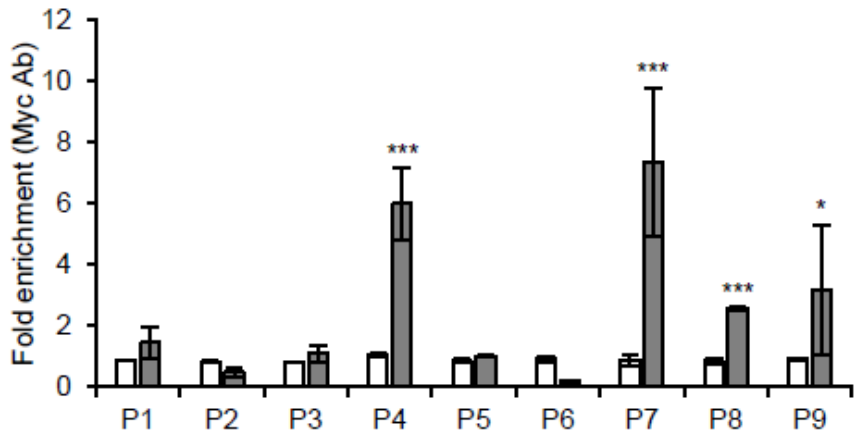

B

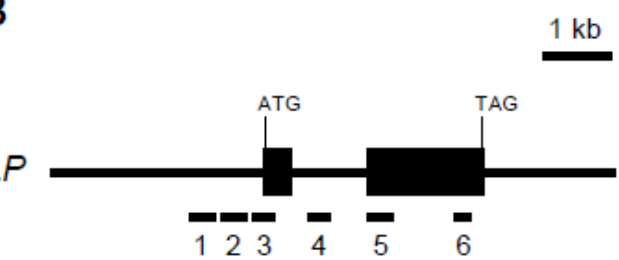

D

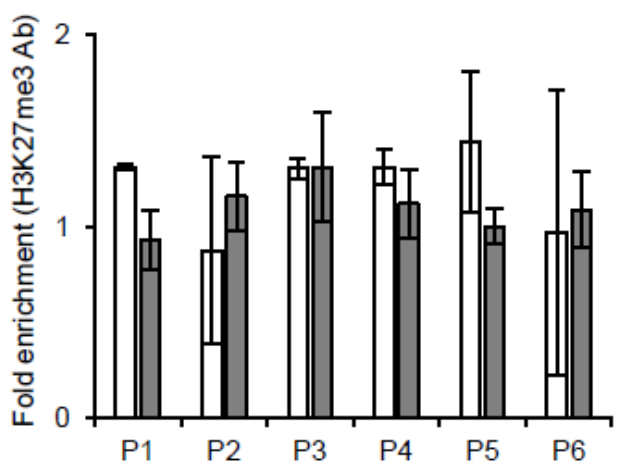

$\mathbf{F}$

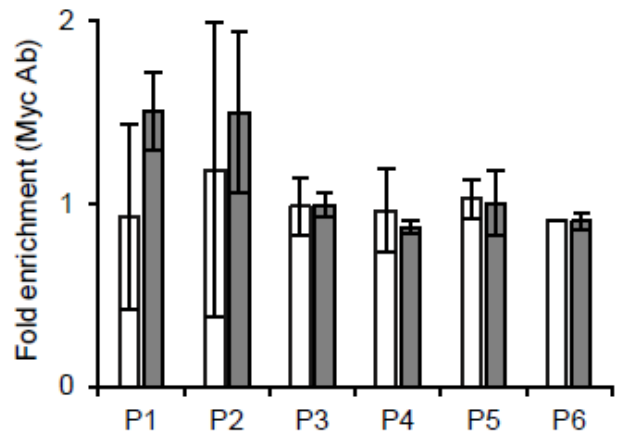

Figure 7. Chromatin immunoprecipitation assay of OsVIL1 in OsCKX2 chromatin. Samples were prepared from the upper $0.5 \mathrm{~cm}$ of the cell division region in the second internode before the heading stage, $n=10$. (A,B) Genomic structure of OsCKX2 and OsLP. OsVIL1-Myc transgenic plants were used for the chromatin immunoprecipitation assay. As a control, we used Myc-empty transgenic plants. (C,D) Analysis of H3K27me3 chromatin states in OsCKX2 chromatin (C) and OsLP (D). (E,F) Enrichment of OsCKX2 (E) and OsLP (F) chromatin in OsVIL1-Myc transgenic plants. The entire experiment was conducted three times and the graph shown are from one of the three experiments. The error bars indicate the standard deviations. Statistical significance is indicated by ${ }^{* * *}(p<0.001)$, $*(p<0.01)$.

\section{Discussion}

\subsection{OsVIL1 Is Involved in Chromatin Remodeling in Rice}

The rice genome contains four VIN3-like genes (OsVIL1-OsVIL4) that are homologous to Arabidopsis VIN3 [31]. They are composed of a PHD finger that is a conserved motif for histone binding, an FNIII domain, and a VID domain [20,21,25]. The PHD finger of OsVIL2 binds to the native histone $\mathrm{H} 3$ in vitro and induces $\mathrm{H} 3 \mathrm{~K} 27 \mathrm{me} 3$ histone modification in the chromatin of target genes $[7,23]$. In this study, we showed that OsVIL1 also modifies chromatin states by regulating H3K27me3 to repress the expression of down-stream genes. $\mathrm{H} 3 \mathrm{~K} 27 \mathrm{me} 3$ is an epigenetic modification of histone $\mathrm{H} 3$ and affects the stability and plasticity of gene regulation during various developmental processes. The chromatin interacting factor of OsVIL2 binds to OsEMF2b, which is a core protein in the PRC2 complex, and 
induces flowering by repressing OsLFL1 in rice [23]. The osvil2 null mutants display late flowering phenotypes, as do OsEMF2b mutants. Although OsVIL2 OX plants display increased biomass and grain yield, the overexpression of OsEMF2 $b$ does not (unpublished data). Similar to OsVIL2, OsVIL1 represses the expression of target genes by inducing H3K27meMoreover, OsVIL1 binds to OsEMF2b through the FNIII domain [25]. However, further studies are needed to elucidate the molecular mechanisms that underlie how the interactions between the OsVIL proteins and OsEMF2b control biomass and grain yield in rice.

\subsection{VIN3-like Proteins Regulate Cell Division of Meristem in Rice}

Vernalization is an acceleration of floral transition from vegetative growth to reproductive growth after exposure to a prolonged period of low temperature [31-33]. In Arabidopsis, VIN3 that is a repressive chromatin-remodeling component is induced only after perceiving a sufficient duration of cold [34,35]. The VIN3 protein induces the trimethylation of $\mathrm{H} 3 \mathrm{~K} 27$ of the target loci to regulate gene expression. For example, VIN3 increases the levels of H3K27me3 in the FLC chromatin region and other FLC clade members [18]. Rice does not require vernalization to control flowering time, and no $F L C$-homologous gene is present in rice [23]. Although the detailed mechanisms for controlling flowering time differ between rice and Arabidopsis, the OsVIL1 and OsVIL2 proteins in rice play a role in promoting flowering by reducing the expression of OsLFL1, a flowering repressor [23,25].

In rice, osvil2 null mutants display pleiotropic phenotypes, including altered flowering times, reduced tiller numbers, alterations in the leaf angles, and defects in floral organ development $[23,26,27]$. In addition, OsVIL2 OX plants exhibit increased biomass and grain yields caused by an accumulation of active cytokinin [7]. In this study, we showed that overexpression of OsVIL1 led to similar phenotypes as those seen in OsVIL2 OX plants, including increased biomass and grain yield. When we examined the histone modification states of OsCKX2 chromatin, a gene responsible for cytokinin degradation, OsVIL1 affected trimethylation of H3K27 in OsCKX2 chromatin, similarly to OsVIL2. Cytokinin plays an essential role in cell proliferation and regulating the size of meristem [4]. In rice, the VIN3like proteins OsVIL1 and OsVIL2 repressed OsCKX2 expression to create a balance between cytokinin synthesis and catabolism to control meristem activity and cell proliferation. In light of these results, it will be interesting to study how VIN3-like proteins in other plant species differ from those in rice and Arabidopsis.

\subsection{Loss-of-Function of OsVIL1 Causes a Reduction in Fertility}

Although similar phenotypes were seen when OsVIL1 or OsVIL2 were overexpressed, the osvil1 null mutants did not show remarkable developmental phenotypes in contrast with osvil2 null mutants, which exhibit pleiotropic phenotypes. Because both OsVIL1 and OsVIL2 induced the trimethylation of H3K27 in the OsCKX2 chromatin region, we expected that their PHD domains would share similar conserved target loci. In addition, OsVIL1 and OsVIL2 bind to OsEMF2b, the core protein of the PRC2 complex, through the FNIII domain. OsEMF2b null mutants display abnormal floral organ identity, reduced tiller size, and pleiotropic phenotypes as in osvil2 null mutants [23]. For these reasons, we suggested that OsVIL2 functions with OsEMF2b in the PRC2 complex to regulate cell division and meristem identity. The null mutants in OsVIL1 did not cause observable developmental defects except in fertilization, suggesting that OsVIL2 can rescue most of OsVIL1 functions. The cause of the reduced fertility of the osvil1 mutant has not yet been clearly identified. The osvil2 has no research results on pollen or the anther development because the floral organ is completely broken in this mutant. The OsEMF2b, interaction partner of OsVIL1 and OsVIL2, functions in anther and pollen development in rice [36]. Both OsVIL1 and OsVIL2 are expected to plays a role in anther and pollen development, but further studies are needed to identify more detailed functions.

However, biomass and grain yield increased when OsVIL1 was overexpressed, indicating that OsVIL1 serves to assist the functions of OsVIL2 in regulating cell division 
and meristem activity. Further study, such as generation of double, triple, or quadruple mutants of OsVIL gene mutants, is required to reveal detailed molecular mechanisms of interaction among the four OsVIL proteins to determine how they regulate various developmental processes.

\section{Materials and Methods}

\subsection{Plant Materials and Growth Conditions}

Oryza sativa var. japonica cultivar Nipponbare was used to generate transgenic plants. Target regions for the CRISPR/Cas9-induced osvil1 KO mutants were genotyped through sequencing (Table S1). For DNA sequencing of the target regions, PCR products were gel purified using $P f u$ polymerase and subjected to subcloning. More than 10 transformed E.coli colonies for each line were then randomly picked up and sequenced. DNA mutations were subsequently identified through sequence alignment between sequenced alleles and WT alleles using NCBI BLAST (https: / / blast.ncbi.nlm.nih.gov (accessed on 1 November 2021). Seeds were germinated either on an MS medium or in soil. We selected two $\mathrm{T}_{0}$ lines that highly expressed the introduced OsVIL1 and renamed the recombinant gene OX \#1 and \#The $\mathrm{T}_{1}$ progeny were grown on an MS medium containing $40 \mu \mathrm{g} \mathrm{mL}^{-1}$ hygromycin. Finally, plants were grown either in the paddy field or a controlled growth room under a light/dark cycle $\left(14.5\right.$-h light at $28{ }^{\circ} \mathrm{C} / 10$-h dark at $23{ }^{\circ} \mathrm{C} ; 50 \%$ humidity) as previously reported [37].

\subsection{Vector Construction and Rice Transformation}

To generate OsVIL1 OX plants and Myc-tagged transgenic plants, OsVIL1 full-length complementary DNA (cDNA) was amplified and digested with restriction enzymes SpeI and SacI, and inserted into binary vector pGA3426 that contains the maize Ubiquitin 1 (Ubi1) promoter, or pGA3438 that contains the maize Ubiquitin1 (Ubi1) promoter and Myc epitope [38]. To construct the CRISPR/Cas9 plasmid, the target sequence was cloned into the entry vector pOs-sgRNA; then, the target sequence and sgRNA were further cloned into a destination vector, $\mathrm{pH}-\mathrm{Ubi}$-cas9-7, using the Gateway ${ }^{\mathrm{TM}}$ system as previously reported [39,40]. The constructs were introduced into Agrobacterium tumefaciens LBA4404 using the freeze-thaw method [41]. Rice transformation via Agrobacterium-mediated cocultivation was performed as previously described [42]. All primers used for cloning are listed in Table S1.

\subsection{RNA Extraction and Real-Time PCR Analysis}

For RNA extraction, $0.5-\mathrm{cm}$ samples were collected from the leaf blades or basal parts of the first and second internodes. Total RNA was isolated with RNAiso Plus (Takara, Kyoto, Japan) and $2 \mu \mathrm{g}$ of total RNA were annealed with $10 \mathrm{ng}$ of oligo (dT). First-strand cDNA was synthesized with Moloney murine leukemia virus reverse transcriptase (Promega, Fitchburg, WI, USA), RNasin (Promega, Fitchburg, WI, USA), and $2.5 \mathrm{mM}$ deoxyribonucleotide triphosphate. Transcript levels were analyzed by quantitative RT-PCR (qRT-PCR) with SYBR Green I Prime Q-Master mix (GENETBIO, Daejeon, Korea) in a Rotor-Gene Q system (Qiagen, Hilden, Germany) [39]. For normalization, we used rice gene Ubiquitin1 (OsUbi1) or Actin1 (OsActin1) as an internal control. The relative expression level was calculated using the $\Delta \Delta \mathrm{Ct}$ method. All primers used for qRT-PCR are listed in Table S1.

\subsection{Histochemical Analysis}

To observe internode development, we used paraffin to obtain sections from the samples of the first internode. The samples were collected from the basal and middle parts of the first internode, and fixed with FAA solution as previously reported [43]. Then, samples were dehydrated and infiltrated with paraffin before being embedded in the embedding ring. Samples were cut to a thickness of $10 \mu \mathrm{m}$, rehydrated, and stained with toluidine blue to observe cell differentiation and elongation. Samples were visualized using a BX61 microscope (Olympus, Tokyo, Japan). 


\subsection{Chromatin Immunoprecipitation (ChIP) Analysis}

Transgenic plants expressing OsVIL1-Myc were used for ChIP analysis as previously reported [44]. Briefly, about $2 \mathrm{~g}$ of the basal parts from the second internodes were collected and incubated in 3\% formaldehyde; then, the nuclei were isolated. Chromatins were fragmented to approximately 500 to $1000 \mathrm{bp}$ lengths by sonication. Before preclearing, $1 \%$ of the sample was gathered as an input. For immunoprecipitation, we used antiMyc monoclonal antibodies (\#2276; Cell Signaling, Bethesda, MD, USA) as described previously $[23,39]$. Data were normalized according to the percentage input method as reported previously [45]. The primer sequences used for the ChIP assays are listed in Table S1. All experiments were conducted at least three times, each involving three biological replicates.

\subsection{Statistical Analyses}

Using R software, the $p$ values were obtained by using one-way analysis of variance (ANOVA; Tukey's HSD test) for the test groups [46].

\subsection{Phylogenetic Analysis}

The orthologous and/or closely paralogous OsVIL1 genes among the 44 representative plants were identified, using an OrthoFinder pipeline (version 2.5.1) [47]. Afterward, phylogenetic relationships among these VIL genes were retrieved as previously reported [48] Briefly, multiple alignment of the coding sequences from identified VIL genes were aligned using MAFFT (version 7.243) [49]. Next, the Neighbor-Joining (NJ) phylogenetic tree was inferred through MEGA6 [50] with bootstraps = 1000 .

\subsection{Meta-Expression Analysis}

To analyze tissue specific expression patterns of OsVIL genes, we used a CAFRI-Rice database site (http:/ / cafri-rice.khu.ac.kr/inspector (accessed on 20 December 2021) [51] based on public available rice Affymetrix microarray data set from the NCBI Gene Expression Omnibus (GEO). The expression values are normalized by $\mathrm{R}$ language and then turned into $\log 2$ values. With downloaded $\log 2$ expression values, we constructed the heatmap with TB tools program [52].

Supplementary Materials: The following are available online at https://www.mdpi.com/article/ 10.3390 /plants11010083/s1, Figure S1. Expression pattern heatmaps of OsVIL genes; Figure S2. Longitudinal section of the first internode; Table S1. Primers used for this study.

Author Contributions: Conceptualization, J.Y. (Jinmi Yoon), H.-J.J., G.A. and L.-H.C.; Formal analysis, J.Y. (Jinmi Yoon), H.-J.J., J.Y. (Jungil Yang), X.P. and L.-H.C.; Investigation, J.Y. (Jinmi Yoon), H.-J.J., G.B., J.Y. (Jungil Yang), X.P., W.T. and S.-T.K.; Supervision, G.A. and L.-H.C.; Writing—original draft, J.Y. (Jinmi Yoon), G.A. and L.-H.C. All authors have read and agreed to the published version of the manuscript.

Funding: This work was supported by a 2-Year Research Grant of Pusan National University.

Institutional Review Board Statement: Not applicable.

Informed Consent Statement: Not applicable.

Data Availability Statement: All data is comprised in the manuscript.

Acknowledgments: We thank Kyungsook An for managing the T-DNA tagging lines and handling the seed stock.

Conflicts of Interest: The authors declare no conflict of interest. 


\section{References}

1. Wu, Y.; Wang, Y.; Mi, X.F.; Shan, J.X.; Li, X.M.; Xu, J.L.; Lin, H.X. The QTP GNP1 encodes GA20ox1, which increases grain number and yield by increasing cytokinin activity in rice panicle meristem. PLoS Genet. 2016, 12, e1006386. [CrossRef]

2. Wang, C.; Yang, X.; Li, G. Molecular insights into inflorescence meristem specification for yield potential in cereal crops. Int. J. Mol. Sci. 2021, 22, 3508. [CrossRef]

3. Kurakawa, T.; Ueda, N.; Maekawa, M.; Kobayashi, K.; Kojima, M.; Nagato, Y.; Sakakibara, H.; Kyozuka, J. Direct control of shoot meristem activity by a cytokinin-activating enzyme. Nature 2007, 445, 652-655. [CrossRef]

4. Jameson, P.E.; Song, J. Cytokinin: A key driver of seed yield. J. Exp. Bot. 2015, 67, 593-606. [CrossRef]

5. Bartrina, I.; Otto, E.; Strnad, M.; Werner, T.; Schmulling, T. Cytokinin regulates the activity of reproductive meristems, flower organ size, ovule formation, and thus seed yield in Arabidopsis thaliana. Plant Cell 2011, 23, 69-80. [CrossRef]

6. Ashikari, M.; Sakakibara, H.; Lin, S.; Yamamoto, T.; Takashi, T.; Nishimura, A.; Angeles, E.R.; Qian, Q.; Kitano, H.; Matsuoka, M. Cytokinin oxidase regulates rice grain productivity. Science 2005, 309, 741-745. [CrossRef]

7. Yang, J.; Cho, L.H.; Yoon, J.; Yoon, H.; Wai, A.H.; Hong, W.J.; Han, M.; Sakakibara, H.; Liang, W.; Jung, K.H.; et al. Chromatin interacting factor OsVIL2 increases biomass and rice grain yield. Plant Biotechnol. J. 2019, 17, 178-187. [CrossRef]

8. Yeh, S.Y.; Chen, H.W.; Ng, C.Y.; Lin, C.Y.; Tseng, T.H.; Li, W.H.; Ku, M.S.B. Down-regulation of Cytokinin Oxidase 2 expression increases tiller number and improves rice yield. Rice 2015, 8, 36. [CrossRef]

9. Li, S.; Zhao, B.; Yuan, D.; Duan, M.; Qian, Q.; Tang, L.; Wang, B.; Liu, X.; Zhang, J.; Wang, J.; et al. Rice zinc finger protein DST enhances grain production through controlling Gn1a/OsCKX2 expression. Proc. Natl. Acad. Sci. USA 2013, 110, 3167-3172 [CrossRef]

10. Li, M.; Tang, D.; Wang, K.; Wu, X.; Lu, L.; Yu, H.; Gu, M.; Yan, C.; Cheng, Z. Mutations in the F-box gene LARGER PANICLE improve the panicle architecture and enhance the grain yield in rice. Plant Biotechnol. J. 2011, 9, 1002-1013. [CrossRef]

11. Molitor, A.; Shen, W.H. The polycomb complex PRC1: Composition and functions in plants. J. Genet. Genom. 2013, 40, 231-238. [CrossRef]

12. Kim, D.H.; Sung, S. Polycomb-mediated gene silencing in Arabidopsis thaliana. Mol. Cells 2014, 37, 841-850. [CrossRef]

13. Mozgova, I.; Henning, L. The polycomb group protein regulatory network. Annu. Rev. Plant Biol. 2015, 66, 269-296. [CrossRef]

14. Yan, B.; Lv, Y.; Zhao, C.; Wang, X. Knowing when to silence: Roles of polycomb-group proteins in SAM maintenance, root development, and developmental phase transition. Int. J. Mol. Sci. 2020, 21, 5871. [CrossRef]

15. De Lucia, F.; Crevillen, P.; Jones, A.M.; Greb, T.; Dean, C. A PHD-polycomb repressive complex 2 triggers the epigenetic silencing of FLC during vernalization. Proc. Natl. Acad. Sci. USA 2008, 105, 16831-16836. [CrossRef]

16. Qiu, Y.; Liu, S.L.; Adams, K.L. Concerted divergence after gene duplication in polycomb repressive complexes. Plant Physiol. 2017, 174, 1192-1204. [CrossRef]

17. Sheldon, C.C.; Finnegan, E.J.; Peacock, W.J.; Dennis, E.S. Mechanisms of gene repression by vernalization in Arabidopsis. Plant J. 2009, 59, 488-498. [CrossRef]

18. Sung, S.; Amasino, R.M. Vernalization in Arabidopsis thaliana is mediated by the PHD finger protein VIN3. Nature 2004, 427, 159-164. [CrossRef]

19. Wood, C.C.; Robertson, M.; Tanner, G.; Peacock, W.J.; Dennis, E.S.; Helliwell, C.A. The Arabidopsis thaliana vernalization response requires a polycomb-like protein complex that also includes VERNALIZATION INSENSITIVE 3. Proc. Natl. Acad. Sci. USA 2006, 103, 14631-14636. [CrossRef]

20. Sung, S.; Schmitz, R.J.; Amasino, R.M. A PHD finger protein involved in both the vernalization and photoperiod pathways in Arabidopsis. Genes Dev. 2006, 20, 3244-3248. [CrossRef]

21. Greb, T.; Mylne, J.S.; Crevillen, P.; Geraldo, N.; An, H.; Gendall, A.R.; Dean, C. The PHD finger protein VRN5 functions in the epigenetic silencing of Arabidopsis FLC. Curr. Biol. 2007, 17, 73-78. [CrossRef]

22. Zhao, S.Q.; Hu, J.; Guo, L.B.; Qian, Q.; Xue, H.W. Rice leaf inclination2, a VIN3-like protein, regulates leaf angle through modulating cell division of the collar. Cell Res. 2010, 20, 935-947. [CrossRef] [PubMed]

23. Yang, J.; Lee, S.; Hang, R.; Kim, S.R.; Lee, Y.S.; Cao, X.; Amasino, R.; An, G. OsVIL2 functions with PRC2 to induce flowering by repressing OsLFL1 in rice. Plant J. 2013, 73, 566-578. [CrossRef]

24. Wang, J.; Hu, J.; Qian, Q.; Xue, H.W. LC2 and OsVIL2 promote rice flowering by photoperiod-induced epigenetic silencing of OsLF. Mol. Plant. 2013, 6, 514-527. [CrossRef]

25. Jeong, H.J.; Yang, J.; Cho, L.H.; An, G. OsVIL1 controls flowering time in rice by suppressing OsLF under short days and by inducing Ghd7 under long days. Plant Cell Rep. 2016, 35, 905-920. [CrossRef]

26. Yoon, H.; Yang, J.; Liang, W.; Zhang, D.; An, G. OsVIL2 regulates spikelet development by controlling regulatory genes in Oryza sativa. Front. Plant Sci. 2018, 9, 102. [CrossRef]

27. Yoon, J.; Cho, L.H.; Lee, S.; Pasriga, R.; Tun, W.; Yang, J.; Yoon, H.; Jeong, H.J.; Jeon, J.S.; An, G. Chromatin interacting factor OsVIL2 is required for outgrowth of axillary buds in rice. Mol. Cells 2019, 42, 858-868. [PubMed]

28. Hsieh, K.T.; Chen, Y.T.; Hu, T.J.; Lin, S.M.; Hsieh, C.H.; Liu, S.H.; Shiue, S.Y.; Lo, S.F.; Wang, I.W.; Tseng, C.S.; et al. Comparisons within the Rice GA 2-Oxidase gene family revealed three dominant paralogs and a functional attenuated gene that led to the identification of four amino acid variants associated with GA deactivation capability. Rice 2021, 14, 70. [CrossRef]

29. Miura, K.; Ikeda, M.; Matsubara, A.; Song, X.J.; Ito, M.; Asano, K.; Matsuoka, M.; Kitano, H.; Ashikari, M. OsSPL14 promotes panicle branching and higher grain productivity in rice. Nat. Genet. 2010, 42, 545-549. [CrossRef] 
30. Jiao, Y.; Wang, Y.; Xue, D.; Wang, J.; Yan, M.; Liu, G.; Dong, G.; Zeng, D.; Lu, Z.; Zhu, X.; et al. Regulation of OsSPL14 by OsmiR156 defines ideal plant architecture in rice. Nat. Genet. 2010, 42, 541-544. [CrossRef]

31. Fu, D.; Dunbar, M.; Dubcovsky, J. Wheat VIN3-like PHD finger genes are up-regulated by vernalization. Mol. Genet. Genom. 2007, 277, 301-313. [CrossRef]

32. Sung, S.; Amasino, R.M. Vernalization and epigenetics:how plants remember winter. Curr. Opin. Plant Biol. 2004, 7, 4-10. [CrossRef]

33. Amasino, R.M. Vernalization and flowering time. Curr. Opin. Biotechnol. 2005, 16, 154-158. [CrossRef]

34. Kim, D.H.; Zografos, B.R.; Sung, S. Vernalization-mediated VIN3 induction overcomes the LIKE-HETEROCHROMATIN PROTEIN1/POLYCOMB REPRESSION COMPLEX2-mediated epigenetic repression. Plant Physiol. 2010, 154, 949-957. [CrossRef]

35. Kim, D.H.; Sung, S. Coordination of the vernalization response through a VIN3 and FLC gene family regulatory network in Arabidopsis. Plant Cell 2013, 25, 454-469. [CrossRef] [PubMed]

36. Deng, L.; Zhang, S.; Wang, G.; Fan, S.; Li, M.; Chen, W.; Tu, B.; Tan, J.; Wang, Y.; Ma, B.; et al. Down-regulation of OsEMF2b caused semi-sterility due to anther and pollen development defects in rice. Front. Plant Sci. 2017, 8, 1998. [CrossRef]

37. Cho, L.H.; Yoon, J.; Pasriga, R.; An, G. Homodimerization of Ehd1 is required to induce flowering in rice. Plant Physiol. 2016, 170, 2159-2171. [CrossRef] [PubMed]

38. Kim, S.R.; Lee, D.Y.; Yang, J.I.; Moon, S.; An, G. Cloning vectors for rice. J. Plant Biol. 2009, 52, 73-79. [CrossRef]

39. Cho, L.H.; Yoon, J.; Wai, A.H.; An, G. Histone deacetylase 701 (HDT701) induces flowering in rice by modulating expression of OsIDS. Mol. Cells 2018, 41, 665-675. [PubMed]

40. Yoon, J.; Cho, L.H.; Kim, S.R.; Tun, W.; Peng, X.; Pasriga, R.; Moon, S.; Hong, W.J.; Ji, H.; Jung, K.H.; et al. CTP synthase is essential for early endosperm development by regulating nuclei spacing. Plant Biotechnol. J. 2021, 19, 2177-2191. [CrossRef]

41. An, G.; Ebert, P.R.; Mitra, A.; Ha, S.B. Binary vectors. In Plant Molecular Biology Manual; Kluwer Academic Publisher A3: Dordrecht, The Netherlands, 1988; pp. 1-19.

42. Jeon, J.S.; Lee, S.; Jung, K.H.; Jun, S.H.; Jeong, D.H.; Lee, J.; Kim, C.; Jang, S.; Lee, S.; Yang, K. T-DNA insertional mutagenesis for functional genomics in rice. Plant J. 2000, 22, 561-570. [CrossRef]

43. Yoon, J.; Cho, L.H.; Antt, H.W.; Koh, H.J.; An, G. KNOX protein OSH15 induces grain shattering by repressing lignin biosynthesis genes. Plant Physiol. 2017, 174, 312-325. [CrossRef]

44. Yoon, J.; Cho, L.H.; Yang, W.; Pasriga, R.; Wu, Y.; Hong, W.J.; Bureau, C.; Wi, S.J.; Zhang, T.; Wang, R.; et al. Homeobox transcription factor OsZHD2 promotes root meristem activity in rice by inducing ethylene biosynthesis. J. Exp. Bot. 2020, 71, 5348-5364. [CrossRef]

45. Haring, M.; Offermann, S.; Danker, T.; Horst, I.; Peterhansel, C.; Stam, M. Chromatin immunoprecipitation: Optimization, quantitative analysis and data normalization. Plant Methods 2007, 3, 1-16. [CrossRef]

46. Cohen, Y.; Cohen, J.Y. Analysis of Variance, in Statistics and Data with R: An Applied Approach through Examples; John Willey \& Sons Ltd.: Chichester, UK, 2008; pp. 417-461.

47. Emms, D.M.; Kelly, S. OrthoFinder: Phylogenetic orthology inference for comparative genomics. Genome Biol. 2019, 20 , 1-14. [CrossRef] [PubMed]

48. Peng, X.; Tun, W.; Dai, S.; Li, J.; Zhang, Q.; Yin, G.; Yoon, J.; Cho, L.H.; An, G.; Gao, L. Genome-wide identify genes contributing to photoperiodic flowering in Oryza rufipogon. Front. Plant Sci. 2021, 12, 736419. [CrossRef] [PubMed]

49. Katoh, K.; Standley, D.M. MAFFT multiple sequence alignment software version 7: Improvements in performance and usability. Mol. Biol. Evol. 2013, 30, 772-780. [CrossRef] [PubMed]

50. Tamura, K.; Stecher, G.; Peterson, D.; Filipski, A.; Kumar, S. MEGA6: Molecular evolutionary genetics analysis version 6. Mol. Biol. Evol. 2013, 30, 2725-2729. [CrossRef]

51. Hong, W.J.; Kim, Y.J.; Kim, E.J.; Chandran, A.K.N.; Moon, S.; Gho, Y.; Yoou, M.H.; Kim, S.T.; Jung, K.H. CAFRI-rice: CRISPR applicable functional redundancy inspector to accelerate functional genomics in rice. Plant J. 2020, 104, 532-545. [CrossRef]

52. Chen, C.; Chen, H.; Zhang, Y.; Thomas, H.R.; Frank, M.H.; He, Y.; Xia, R. TBtools: An integrative toolkit developed for interactive analyses of big biological data. Mol. Plant 2020, 13, 1194-1202. [CrossRef] 